\title{
Educación sexual y género en primarias mexicanas ¿qué dicen los libros de texto y el profesorado?
}

\author{
Sex Education and Gender in Mexican Elementary Schools: What Do Textbooks and \\ Teachers Have to Say?
}

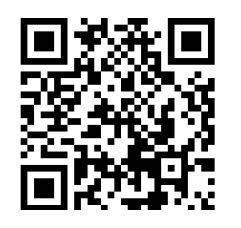

Recibido 17 de marzo de 2016 • Corregido 21 de marzo de 2017 • Aceptado 17 de abril de 2017

\begin{abstract}
Resumen: El objetivo de esta investigación fue revisar y analizar, desde la perspectiva de género, los contenidos de sexualidad y género incluidos en los libros de texto de Ciencias Naturales y Formación Cívica y Ética de cuarto, quinto y sexto grados de primaria del ciclo escolar 2015-2016 (ediciones 2014), para señalar los aciertos y deficiencias en cuanto a su abordaje. Además, indagamos sobre la formación profesional docente en sexualidad y género, para lo cual nos basamos en testimonios de cuatro entrevistas efectuadas al profesorado de primaria de los Estados del sureste mexicano de Quintana Roo y Yucatán: dos de quinto grado y dos de sexto. Los resultados muestran que los contenidos de los libros de texto reducen la sexualidad a la reproducción, y no incorporan el erotismo, el cual es considerado relevante en el enfoque de educación integral de la sexualidad. Asimismo, transmiten ideas heteronormativas sobre las vinculaciones afectivas, y no incorporan la perspectiva de género a cabalidad, ya que fracasan en denunciar la desigualdad entre hombres y mujeres. La formación de docentes es deficiente y hace evidente la operación del currículo oculto, pues se transmiten estereotipos y prejuicios de género y sexualidad.
\end{abstract}

Palabras claves: Educación sexual; género; programa de estudios; docente de escuela primaria; formación de profesores.

\footnotetext{
${ }^{1}$ Doctora en Ciencias Antropológicas, UAM. Profesora-investigadora Titular C, Universidad Pedagógica Nacional. Miembro del Sistema Nacional de Investigadores. Nivel 2. Temas de investigación: educación, género, sexualidad, derechos humanos, migración, poblaciones mayas Quintana Roo, Yucatán y Campeche.

2 Doctor en Psicología, UNAM. Profesor-investigador Titular A, Universidad Pedagógica Nacional. Miembro del Sistema Nacional de Investigadores. Nivel candidato. Temas de investigación: educación, parentalidad, desarrollo infanto-juvenil, género y sexualidad.
} 
doi: http://dx.doi.org/10.15359/ree.21-2.11

URL: http://www.una.ac.cr/educare

CORREO: educare@una.cr

\begin{abstract}
The aim of this research was to review and analyze, from a gender perspective, the sexuality and gender contents included in the textbooks of Natural Sciences, Civics, and Ethics for the fourth, fifth and sixth grade of elementary school; this was done to point out the strengths and weaknesses on how to address these issues. We, likewise, inquired about teacher training in sexuality and gender topics, for which we relied on the testimony of four interviews with primary school teachers from Quintana Roo and Yucatán (two states of the Mexican southeast): two of them were from fifth grade, and two others were from sixth grade. The results showed that the contents of the textbooks reduce the sexuality topic to reproduction, and they do not include eroticism, which is considered relevant in the approach to comprehensive sexuality education. Similarly, these contents transmit heteronormative ideas regarding emotional bonds, and do not fully incorporate the gender perspective, since they fail to denounce the inequality between men and women. Teacher training is deficient and it emphasizes the effect of the hidden curriculum, as stereotypes and prejudices of gender and sexuality are being transmitted.
\end{abstract}

Keywords: Sex Education; Gender; Curriculum; Primary School Teacher; Professional Training.

Los contenidos curriculares de educación integral de la sexualidad (EIS), así como la formación de docentes de nivel primaria en esa área, constituyen una preocupación del sistema educativo nacional mexicano, sobre todo a partir de que se estableció la Agenda sectorial de educación integral de la sexualidad, con énfasis en la prevención del embarazo en adolescentes (Secretaría de Educación Pública, SEP, 2015).

De acuerdo con dicha Agenda, a partir de la Reforma Integral de la Educación Básica $(\text { RIEB })^{3}$ de 2011 , se planteó que en cada uno de los niveles y grados de educación básica se trabajarían las competencias para la vida (conocimientos, habilidades y actitudes), y en educación sexual, particularmente el tema de valores enfocado a la diversidad, equidad de género, salud, prevención de la violencia y derechos humanos (SEP, 2015). También se estipuló que los contenidos particulares sobre educación sexual en cada grado escolar se diseñarían pensando en la madurez emocional de las niñas y los niños, por lo que de primero a cuarto grado se incluyeron exclusivamente contenidos en torno a las partes y funciones del cuerpo humano de acuerdo con el sexo biológico, y en quinto y sexto grados, sobre el ciclo menstrual, fecundación, embarazo, metodología anticonceptiva, infecciones de transmisión sexual (ITS), VIH-sida, virus del papiloma humano (VPH), abuso sexual y violencia de género (SEP, 2015).

En este trabajo aportamos a la discusión en torno al diseño de programas y contenidos de EIS en educación básica, y en cuanto a la apremiante necesidad de formar maestros y maestras en temas de sexualidad, con perspectiva de género. El análisis de los contenidos y testimonios de entrevistas lo efectuamos a través de una mirada de género, poniendo en evidencia elementos del currículo oculto, pues este permite el "análisis de los elementos fundamentales

${ }^{3}$ Las reformas educativas se implementaron en 2004 en preescolar; en 2006 en secundaria, y, en 2009 en primaria. 
en la producción de un orden pedagógico [que] designa el proceso de transmisión de normas implícitas, valores y creencias que subyacen en las formas culturales utilizadas en la escuela" (Parga, 2008, p. 41). Además, mucho de lo que se enseña en el aula, y muy particularmente en el ámbito de la sexualidad, se orienta por el aprendizaje de valores.

[Ello] guarda una relación estrecha con el currículum oculto [y este a su vez] tiene una estrecha relación con lo que se actúa, más que con la información de qué se dice ... la actuación, los códigos empleados en la comunicación, las formas de decir o afirmar una cosa no necesariamente convergen con lo que se dice en el plano explícito. (Díaz, 2006, p. 8).

La educación integral de la sexualidad, definida como aquella que incluye distintos aspectos de la sexualidad, y no solo su dimensión biológica, se ha colocado como un tema de la política educativa en México; aunque no ha alcanzado todos los niveles educativos. Por tal motivo, realizamos una revisión crítica y sistemática de los libros de texto de primaria en los que se explica la sexualidad y el género, para analizar, con una perspectiva de género, sus contenidos. Para ello, construimos cuadros analíticos en los que situamos la información recopilada de acuerdo con las categorías que surgieron en las unidades temáticas revisadas en los libros, entre las que destacan: crecimiento, desarrollo, reproducción, embarazo, pubertad, enamoramiento y riesgos del ejercicio sexual. Por otra parte, también desde un enfoque de género, efectuamos entrevistas a docentes de quinto y sexto de primaria, con la finalidad de analizar elementos que nos permitieran conocer sobre su formación en temas de género y sexualidad.

Este artículo contiene dos apartados, en el primero se efectúa un análisis de los contenidos sobre educación sexual en los libros de texto de cuarto a sexto de primaria de las asignaturas de Ciencias Naturales y Educación Cívica y Ética. El segundo, se refiere a la formación en género y sexualidad de docentes de primaria. En la conclusión sugerimos la incorporación de ciertos temas, y subrayamos la necesidad de impulsar la formación de docentes en temas de educación sexual y género.

\section{Sexualidad y género en libros de texto de primaria}

Según la Agenda sectorial de educación integral de la sexualidad, con énfasis en prevención del embarazo en adolescentes (SEP, 2015) en los libros de texto de quinto y sexto de primaria del ciclo escolar 2015-2016 se incluirían orientaciones didácticas sobre la salud sexual (SEP, 2015), no obstante, los libros que se entregaron para ese ciclo son una reimpresión de los de 2014, con una orientación biologicista. En el libro de Ciencias Naturales (SEP, 2014a) de cuarto grado - primer tema del bloque I, se habla de los caracteres sexuales de mujeres y hombres, iniciando con la frase "otra característica común en los seres vivos es la reproducción" (p. 11), luego se aclara que "en este tema estudiaremos el cuerpo humano considerando la relación cercana que guardan sus aparatos y sistemas" (p. 12). Se define el aparato sexual como aquel "que [lleva] a 
doi: http://dx.doi.org/10.15359/ree.21-2.11

URL: http://www.una.ac.cr/educare

CORREO: educare@una.cr

cabo la reproducción: la capacidad que tienen los seres vivos para engendrar nuevos individuos ... en la reproducción humana intervienen un hombre y una mujer" (p. 13). En las siguientes dos páginas se explican los caracteres sexuales primarios y secundarios de niñas y niños, y se muestran diagramas de los aparatos sexuales con sus nombres. Se manifiesta que "al producirse las células sexuales femeninas y masculinas, el cuerpo humano está sexualmente maduro y en condición de procrear" (p. 15), para de ahí pasar a discernir sobre las "semejanzas en las capacidades físicas e intelectuales de hombres y mujeres" (p. 16) (SEP, 2014a).

Apreciamos que la información que se presenta en esta sección es confusa, pues el objetivo indica que se abordará el cuerpo y la relación entre aparatos y sistemas, y no hallamos referencia a algún sistema; además, definir el aparato sexual en términos reproductivos es reducir la sexualidad a una sola de sus posibilidades, sin otra opción que la heterosexualidad. Afirmar que el cuerpo está sexualmente maduro y en condiciones de procrear cuando se producen células femeninas (óvulos) y masculinas (espermatozoides) es incongruente con la Estrategia Nacional para la Prevención del Embarazo en Adolescentes (México Gobierno de la República, 2015), pues se emite un discurso que contradice otros que se encuentran en el libro, como que las niñas y niños de cuarto grado son inmaduros psicológica y socialmente para ejercer la maternidad y la paternidad. En realidad, se transmite un mensaje "oculto" que mira la sexualidad como sinónimo de reproducción, y se refuerza la idea de que una mujer y un hombre solo se vinculan sexualmente para tener hijos o hijas. Además, no se habla ni someramente, de las relaciones sexuales por placer, entre personas del mismo sexo, o entre quienes ya atravesaron por la etapa reproductiva.

El tema tres del bloque I del libro de Ciencias Naturales de quinto grado, "Funcionamiento de los aparatos sexuales y el sistema glandular" (SEP, 2014b, p. 35) ahonda en la anatomía y fisiología del cuerpo de mujeres y hombres; se explican los cambios que ocurren en la pubertad, como el ciclo menstrual y la eyaculación (incluyendo los sueños húmedos), así como los caracteres sexuales secundarios. Al hablar de la fecundación se advierte que, a pesar de estar en condiciones biológicas, "el embarazo en la adolescencia implica riesgos físicos tanto para la madre como para el feto, por lo que es importante evitarlo" (p. 40). Para que el estudiantado obtenga más información, se le remite a una página web que, por su nombre, versa sobre la prevención del embarazo e ITS. Si bien el texto de quinto grado abarca más temáticas que el de cuarto, continúan siendo tabúes las relaciones sexuales, las prácticas de sexo sin reproducción, y las de parejas del mismo sexo; en cambio, se dedica una amplia sección a tratar la higiene del cuerpo, y un espacio no muy extenso para abordar la igualdad entre mujeres y hombres (SEP, 2014b).

El libro de Ciencias Naturales de sexto grado trata el tema de la educación sexual en el bloque I “Cómo mantener la salud?", específicamente en el tema dos, "Etapas del desarrollo humano: la reproducción". Tal y como lo indican los títulos, el énfasis está puesto en la salud reproductiva, de manera que es posible anticipar que no será abordada la EIS cabalmente. Las autoras y los autores mencionan que al finalizar la unidad el estudiantado "[aprenderá] 
a describir los cambios que suceden durante el desarrollo humano; los [identificará] en [su] persona, y [explicará] cómo se lleva a cabo el proceso de reproducción en los seres humanos" (SEP, 2014f, p. 30). Si bien son objetivos trascendentales, abarcan solo una parte del estudio de la sexualidad, lo cual resulta contradictorio con lo establecido en la Agenda sectorial de educación integral de la sexualidad, con énfasis en la prevención del embarazo en adolescentes (SEP, 2015). El libro de Ciencias Naturales de sexto grado propone que la adolescencia inicia con la pubertad, dando mayor énfasis a los cambios físicos:

Tu cuerpo comenzará a ser diferente, tu apariencia física se definirá de acuerdo con tu sexo (mujer u hombre) ... el crecimiento de los senos te indica que tu cuerpo comienza a prepararse para asumir tus responsabilidades y las consecuencias de tus decisiones, lo que puede favorecer una sana convivencia social. (SEP, 2014f, p. 32)

El fragmento anterior resulta sumamente problemático, pues en primer lugar, limita la expresión de la identidad sexo-genérica a la genitalidad; en segundo sitio, retira toda posible connotación erótica del crecimiento y disfrute de los senos, colocándolos como órganos al servicio de la maternidad y, por lo tanto, de los hombres, y por último; da a entender, entre líneas, que una mujer adolescente debe decidir utilizar sus senos exclusivamente para la lactancia y así favorecer la sana convivencia social. Esta cita es una muestra de la operación del currículo oculto en el que se promueve la heteronorma y el patriarcado. Más adelante, se señala que en la adultez "alcanzan su máximo potencial las capacidades físicas y psicológicas del ser humano ... por lo general, se considera que en esta etapa las personas tienen la madurez emocional y física que les permite formar una familia" (SEP, 2014f, pp. 32-33), lo cual es también cuestionable, pues no solo idealiza la figura de la familia como vía exclusiva de realización personal, sino que perpetúa una mirada adultocéntrica en la cual las personas menores de edad son concebidas como incompletas e inmaduras.

Desde la psicología, en 1904, Ganville Stanley Hall definía la adolescencia como "una edad especialmente dramática y tormentosa en la que se producen innumerables tensiones, con inestabilidad, entusiasmo y pasión, en la que el joven se encuentra dividido en tendencias opuestas" (Hall, citado en Dávila, 2004, p. 87). Consideramos que el equipo autor del libro de sexto grado (SEP, 2014f) no toma en cuenta que los conceptos de infancia y adolescencia son construcciones sociales e históricas que se conciben en el siglo XIX, y que se requiere de nuevas aproximaciones a este periodo vital, con miras a no ver a la adolescencia como una época oscura y de crisis, ya que a lo largo de toda la vida ocurren vicisitudes.

En el tema tres "Implicaciones de las relaciones sexuales en la adolescencia"del libro Ciencias Naturales, sexto grado (SEP, 2014f, p. 37) se presenta una viñeta de un niño y una niña escuchando la conversación de la hermana de uno de ellos con una amiga, donde una le dice a la otra: 
doi: http://dx.doi.org/10.15359/ree.21-2.11

URL: http://www.una.ac.cr/educare

CORREO: educare@una.cr

Recuerda que el año pasado en la escuela nos dieron una plática y nos explicaron los riesgos de tener relaciones sexuales a nuestra edad, como contraer alguna infección de transmisión sexual o tener un embarazo no planeado. Además, somos muy valiosas y tenemos muchas cosas que lograr a futuro, jugar, divertirnos y estudiar. (SEP, 2014f, p. 37)

Contraer una ITS o tener un embarazo no planeado no es algo privativo de la juventud, de manera que no son "riesgos de la edad". En segundo lugar, las personas embarazadas o infectadas son igualmente valiosas, y pueden tener metas, por lo cual el párrafo no solo promueve la abstinencia -sin hablarlo abiertamente-, sino que termina siendo, probablemente sin intención de hacerlo, sumamente discriminatorio al sugerir que quienes tienen una ITS o se embarazaron ya no son valiosas ni tienen metas.

Las relaciones sexuales son la base de la reproducción, además de contribuir a la estabilidad de las parejas y a un acercamiento más íntimo. Sin embargo, requieren de una responsabilidad compartida. De ahí que sea indispensable que cuentes con información y orientación. Esto evitará una consecuencia como podría ser un embarazo no planeado o sufrir el contagio de una infección de transmisión sexual (ITS), que pueden cambiar la vida de una persona para siempre. (SEP, 2014f, p. 37)

Si bien es cierto que las relaciones sexuales son la base de la reproducción, no tienen por qué ser concebidas como una actividad exclusiva de parejas estables con conexión emocional. Coincidimos con las autoras y los autores en que es indispensable que cuenten con información y orientación; no obstante, paradójicamente el libro de texto (SEP, 2014f) no brinda información completa y libre de sesgos, por lo que el estudiantado puede pensar que sexualidad es sinónimo de reproducción y de riesgo.

En la página 38 del libro de Ciencias Naturales, sexto grado (SEP, 2014f) las autoras y los autores eligieron utilizar una imagen de una madre joven francamente deprimida con un bebé hipotónico en brazos, incapaz de sostener la cabeza. El pie de la imagen dice "Aunque la menor de edad es madre, su mentalidad, su autonomía y su estilo de vida siguen siendo de una adolescente, por lo que un embarazo a su edad puede generarle conflictos internos y externos" (SEP, 2014f, p. 38). Nos preguntamos si tal imagen y afirmación representan a todas las mujeres jóvenes que se embarazan en países latinoamericanos, pues tal y como argumentamos anteriormente, la adolescencia es un período concebido hace más de un siglo y, además, para poblaciones anglosajonas; esta noción puede ser poco aplicable para mujeres jóvenes rurales e indígenas que en nuestro país obtienen precisamente su estatus de adultas -superior- en cuanto se convierten en madres; lo cual no es conflictivo ni extraño desde su cosmovisión, por lo que habría que tener cuidado con afirmar que "su desarrollo social queda trunco" (SEP, 2014f, p. 38). 
Después de lo que has aprendido, recuerda que nadie te puede obligar ni forzar a tener relaciones sexuales; es una decisión que debes analizar muy bien, con la información adecuada, de modo que tu vida sea plena y estés en condiciones de evitar una consecuencia no deseada como un embarazo no planeado o la adquisición de una infección. (SEP, 2014f, p. 40)

En páginas previas de este libro no se había abordado el tema de explotación/abuso sexual, de manera que la advertencia realizada en la cita anterior queda a nivel discursivo; además, en las siguientes lecciones no se brindan herramientas para conocer con profundidad y reflexionar sobre dichos temas. Al finalizar la unidad, les solicitan al estudiantado que elabore un proyecto intitulado Nuestra sexualidad, brindándoles las siguientes preguntas guía:

¿Dónde puedes obtener información confiable para conocer más acerca de la sexualidad humana? ¿Cuáles son las falsas creencias sobre la sexualidad? ... ¿Cuál es la importancia de los sentimientos y el afecto en la reproducción humana? ¿Qué significa "equidad de género" para ti? ¿Qué significa para ti "sexualidad responsable"? (SEP, 2014f, p. 46)

Si bien son preguntas valiosas, nuevamente se plantean cuestionamientos sin haber dado previamente insumos mínimos para responderlas. Siguiendo esta misma línea, en la autoevaluación correspondiente se solicita que califiquen si pueden explicar"el proceso general de reproducción en los seres humanos: fecundación, embarazo y parto, con énfasis en los aspectos afectivos implicados" (SEP, 2014f, p. 49), sin haber abordado previamente las emociones. En muchos casos se da por hecho que el estudiantado cuenta con elementos para responder a los cuestionamientos indicados.

Antes de continuar con el análisis de los libros de Formación Cívica y Ética, queremos subrayar que el enfoque de riesgo de la sexualidad está fuertemente arraigado en los contenidos de todos los libros que analizamos. Con esta perspectiva, la Secretaría de Educación Pública de México desea promover la toma de decisiones de las niñas y los niños en espacios de sexualidad; no obstante, sugerimos que provocar miedo - a través de la perspectiva de riesgo--y ofrecer información sobre metodología anticonceptiva no han resultado ser estrategias eficaces para prevenir el embarazo temprano, así como las ITS por lo que, evidentemente, se requiere de otras estrategias.

El libro de sexto grado de Formación Cívica y Ética, bloque I "De la niñez a la adolescencia”, primera lección: "Mi crecimiento y desarrollo" hace referencia al de Ciencias Naturales del mismo grado (del que hablamos anteriormente), y explica que la pubertad es "'el despertar de la sexualidad' porque inicia la producción de hormonas -estrógenos en ovarios y testosterona en testículos- que provocan que el cuerpo empiece a transformarse y las personas pasen gradualmente de la niñez a la adultez" (SEP, 2014e, p. 15). La pubertad se asocia con cambios físicos y emocionales, entre los que se cita el "enamoramiento y la atracción sexual" (SEP, 2014e, p. 16) (para las mujeres), y la necesidad de pertenecer a grupos de adolescentes (en los hombres), entre otros, esto a través de algunos dibujos. 
doi: http://dx.doi.org/10.15359/ree.21-2.11

URL: http://www.una.ac.cr/educare

CORREO: educare@una.cr

Consideramos que, al contrario de lo que se afirma en el libro, la sexualidad es una dimensión que está presente durante toda la vida, y comienza en el momento del nacimiento:

De la concepción popular del instinto sexual forma parte la creencia de que falta durante la niñez, no apareciendo hasta el periodo de pubertad. Constituye esta creencia un error de consecuencias graves, pues a ella se debe principalmente nuestro actual desconocimiento de las circunstancias fundamentales de la vida sexual ... parece cierto que el recién nacido trae consigo al mundo impulsos sexuales en germen, que, después de un periodo de desarrollo, van sucumbiendo a una represión progresiva ... los educadores se conducen ... como si supieran que la actividad sexual hace a los niños ineducados, pues persiguen todas las manifestaciones sexuales del niño como "vicios". (Freud, 1994, pp. 40-45)

Si bien, Freud (1989) consideraba una etapa de latencia, en la cual existe una supuesta "amnesia"en relación con las expresiones sexuales, a través de sus estudios arribó a la"convicción de que ningún niño -o por lo menos, ningún niño de inteligencia completa o superior- llega a la pubertad sin que los problemas sexuales hayan ocupado ya su pensamiento en los años anteriores a la misma" (p. 16). Salinas-Quiroz (2014) realizó una investigación sobre la latencia, la cual contiene una revisión histórica del concepto, las características de esta y cómo resulta más pertinente hablar de un trabajo psíquico de la latencia, pues"implica organización, diferenciación, complejización y ampliación del aparato psíquico, así como un reordenamiento dinámico y estructural para lidiar con las pulsiones" (Salinas-Quiroz, 2014, p. 162). Subrayamos la relevancia de algunos de los aportes del psicoanálisis en la comprensión de la sexualidad infantil, con miras a trascender ideas del "sentido común" presentes en el libro de Formación Cívica y Ética de sexto grado (SEP, 2014e), en el cual se afirma que en la pubertad se despierta la sexualidad, debido a cuestiones biológicas, como la producción hormonal.

Por otro lado, el mismo texto (SEP, 2014e) concibe el "enamoramiento y la atracción sexual" como una característica presente en las niñas, aunque no hace referencia a los niños. La concepción de "amor romántico" está condicionada por la normatividad dominante de género que, entre otras cosas, refuerza la idea de que son las mujeres quienes más expresan el amor. En el caso de varones, el texto habla de amistad, pero no de enamoramiento. La atracción sexual indicada para las niñas podría sugerir que ellas manifiestan elementos de la pubertad antes que los niños, lo cual también ha sido cuestionado, inclusive por el propio Freud; no en relación con la diferencia entre niñas y niños, sino de la diversidad presente en los individuos; para él "el influjo de la educación y la distinta intensidad del instinto sexual ha de dar, seguramente, origen a grandes oscilaciones individuales en la conducta sexual infantil, determinando ... la emergencia más o menos temprana del interés sexual" (Freud, 1989, p. 16). 
Las siguientes páginas de esta lección del libro de Formación Cívica y Ética de sexto grado (SEP, 2014e) están dedicadas a realizar actividades para que el estudiantado escriba su propia biografía, y en una sección llamada "participemos" se pide que se redacte una conclusión sobre la relación que tiene la pubertad con la sexualidad, y la importancia de conocerse y aceptarse. Subrayamos que no hay una definición de la sexualidad, más allá de hablar de su inicio en la pubertad, por lo que hay pocos elementos para que las niñas y los niños elaboren una conclusión sobre el vínculo entre pubertad y sexualidad.

La lección dos del bloque I del mismo libro inicia con una serie de cápsulas estadísticas tomadas de la Encuesta Nacional de Salud y Nutrición 2012, para luego canalizar al alumnado a un cuestionario con preguntas como: ¿ ¿Por qué consideran que a pesar de que un alto porcentaje de la población adolescente dice conocer métodos anticonceptivos se siguen presentando casos de embarazo a temprana edad?, o ¿qué otros riesgos relacionados con la salud sexual enfrentan las personas de su edad? Para la segunda pregunta no se había proporcionado aún la definición de salud sexual (se hace en las siguientes páginas del texto) por lo que el estudiantado difícilmente podría dar una respuesta, y la primera pregunta, es la cuestión que ni especialistas ni quienes diseñan o toman decisiones de política pública han podido responder. Además, una cosa es que se conozca de metodología anticonceptiva, y otra, que la juventud tenga acceso a los métodos. La pregunta quizá podría ser: ¿Por qué nos extraña que las niñas y jóvenes tengan hijos o hijas si los libros de texto se afanan en ensalzar la familia heterosexual y la maternidad, y se asume que sexualidad es igual a reproducción? Aunado a esto, no existe una política de salud en donde se atienda la salud sexual de los grupos de jóvenes. Si constantemente se les dice, como ya citamos arriba, que "las relaciones sexuales son la base de la reproducción, además de contribuir a la estabilidad de las parejas y a un acercamiento más íntimo" (SEP, 2014f, p. 37). ¿Podemos pretender que deseen otra cosa? Y más aún: ¿Realmente creemos que los riesgos hacia la salud sexual tienen que ver con la edad? ¿O que generando miedo utilizarán condón?

Posteriormente, en el mismo libro Formación Cívica y Ética de sexto grado (SEP, 2014e), se proporciona una definición de salud sexual y reproductiva que resulta confusa, ya que en el título se anota el concepto, pero la explicación se refiere a una "persona sana":

Comprende los cambios que está viviendo, cuida su higiene y sus órganos sexuales. Sabe que tiene derecho a no ser molestada en su cuerpo ni en su intimidad; a ser tratada con amor y respeto, y a expresar sus afectos sin ser importunada por ello. Tal persona previene las ... ITS y los embarazos, así como la violencia en el noviazgo. (SEP, 2014e, p. 25)

En el libro de Formación Cívica y Ética, sexto grado (SEP, 2014e) se cita el libro de Ciencias Naturales de sexto grado (SEP, 2014f) diciendo que: Ya has estudiado en tus clases... que para conservar la salud sexual y reproductiva, es necesario cuidarse y cuidar a la pareja el inicio de la vida sexual se acompaña de algunos riesgos como las ITS [y] ... un embarazo, que a temprana 
doi: http://dx.doi.org/10.15359/ree.21-2.11

URL: http://www.una.ac.cr/educare

CORREO: educare@una.cr

edad es peligroso tanto para la madre -porque su organismo aún no está preparado para la gestación y el parto- como para el bebé. (SEP, 2014e, p. 26)

Aquí se continúa con el discurso heteronormativo, mediante el cual se deduce que la pareja es siempre heterosexual, ya que se puede producir un embarazo.

Por otra parte, en uno de los recuadros titulado "palabras claras" (SEP, 2014e, p. 28) se explica que no es lo mismo sexo que sexualidad; la primera noción no se delimita, en tanto que la segunda se aborda de manera clara y concisa, aunque mencionando el enfoque de los cuatro holones de la sexualidad ${ }^{4}$ sin profundizar en él (SEP, 2014e). Otro ejercicio (SEP, 2014e) remite al libro de Ciencias Naturales. Sexto grado (SEP, 2014f) y a la página web <http://www.basica. primariatic.sep.gob.mx/> y que trataba sobre prevención de riesgos, con la finalidad de que el alumnado pudiese desarrollar un tema - de libre elección-y hablar sobre la toma de decisiones responsables e informadas (con base en una lista que elaboraron previamente sobre cuáles son las elecciones que deberán tomar antes de finalizar la primaria) (SEP, 2014e). En esta tarea no queda claro cómo estimular la toma de decisiones sobre la sexualidad con base en una lista de decisiones que se deben tomar antes de terminar la primaria.

En otras páginas hay una historieta en la que se trata el tema de la elección sobre las relaciones sexuales; el novio pregunta a la novia: ¿y si damos un paso más?, ella argumenta que no quiere, no está lista, tiene temor del sida o de un embarazo, y él responde:"pues parece que no me quieres". Después hay una serie de preguntas con las que se pretende que el grupo llegue a un punto de acuerdo. La historieta es propositiva, a pesar de que induce a la abstinencia sexual, en lugar de dejar que el estudiantado llegue de manera libre a una conclusión, y continúa transmitiendo el miedo (SEP, 2014e).

En otro recuadro de "palabras claras" se describe, de manera acertada, el riesgo como "aquella situación que representa un peligro para la vida, la dignidad y la seguridad" y la percepción de riesgo como"la capacidad de identificar estas situaciones y medir el peligro" (SEP, 2014e, p. 34). En la parte final de esta lección se presentan varias preguntas, entre ellas: ¿¿Dónde pueden obtener información para tomar mejores decisiones ante una situación de riesgo? ... ¿Qué nuevas responsabilidades personales enfrentan en la adolescencia? ¿Qué personas 0 instituciones brindan orientación acerca de los riesgos que se enfrentan en la adolescencia?" (SEP, 2014e, p. 35). Pensamos que a las personas diseñadoras de la actividad no les queda claro que una cosa es la información que se brinda, y otra muy distinta las decisiones que las personas toman, por lo que saber dónde pueden obtener información u orientación al respecto no necesariamente propiciará mejores elecciones entre estudiantes.

\footnotetext{
${ }^{4}$ En este enfoque, la sexualidad se concibe como la "integración de cuatro potencialidades humanas que dan origen a cuatro holones (o subsistemas) sexuales: la reproductividad, el género, el erotismo y la vinculación afectiva interpersonal (Rubio, 1994, 29).
} 
La lección cuatro del bloque uno de Formación Cívica y Ética de sexto grado trata los estereotipos y prejuicios de género, y se promueve su estudio mediante varios ejercicios como preguntas directas, un cuestionario, y actividades por equipos (realización de un periódico mural), e individuales (analizar estereotipos en la televisión; hoja compromiso "yo promuevo un trato respetuoso y equitativo ¿y tú?") (SEP, 2014e, p. 38) con la finalidad de que el alumnado reflexione sobre estereotipos y prejuicios de género. Al final hay una evaluación grupal para que cada estudiante diga qué sintió, qué aprendió, que cambió y a qué se compromete. Dichas actividades son apropiadas, aunque dependerá de la sensibilidad del personal docente el generar la reflexión crítica sobre los temas propuestos, y hacer que lo "aprendido" se convierta en un conocimiento con sentido y aplicable a la vida personal de cada estudiante.

El libro de texto de Formación cívica y ética de quinto grado (SEP, 2014d), en el bloque I "Niñas y niños que construyen su identidad y previenen riesgos" (p. 14), se refiere a los cambios físicos y emocionales, no obstante, enfatiza los corporales. Introduce también el tema de las decisiones y los riesgos que se enfrentan al inicio de la juventud, como el consumo y el abuso de sustancias adictivas, la bulimia, la anorexia y la obesidad, las cuales, según el texto, se relacionan con la necesidad de aceptación y de pertenencia a grupos etarios, o bien, con la autoestima y la imagen personal. Llama la atención que no se toque el tema de la sexualidad, y la posibilidad de contraer ITS o de un embarazo temprano (SEP, 2014d).

Por otro lado, el currículo oculto de género se manifiesta en el ejercicio del bloque I: "Tu camino de la vida" (SEP, 2014d, p. 17), en donde se presentan dibujos de una mujer en su papel de madre, y a otra mamá que regala un vestido rosa a una niña en su cumpleaños. Estas imágenes promueven estereotipos de género, es decir, guían el proceso de construcción de la identidad de las niñas y los niños, al inducir a las mujeres a utilizar vestidos de ese color, y a visualizarse como madres, y cuidadoras exclusivas de su prole, ya que no aparece un padre. Al explicar los estereotipos, el texto se basa en los de tono de piel, rasgos físicos, estatura o nivel económico (SEP, 2014d), pero no se hace mención a los estereotipos de género.

En el bloque V del libro de Educación Cívica y Ética de quinto grado (SEP, 2014d), "La solución de conflictos sin violencia y con apego a los derechos humanos", en la lección "Formas pacíficas de resolver conflictos", se trata el tema de la violencia, utilizando la definición de la Organización Mundial de la Salud (OMS). No obstante, no se hace referencia a la violencia de género:

La violencia es el uso intencional de la fuerza o el poder para hacer daño.

Se presenta de muchas maneras: con maltratos físicos o psicológicos, mediante actitudes discriminatorias, con abuso de la autoridad, explotación y uso de las personas, o bien, a través de la falta de oportunidades. (SEP, 2014d, p. 183) 
doi: http://dx.doi.org/10.15359/ree.21-2.11

URL: http://www.una.ac.cr/educare

CORREO: educare@una.cr

También hallamos un ejemplo de cómo se transmite el "currículo oculto" de género:

En la vida diaria es habitual que existan conflictos que no se reconocen, a veces porque se ocultan y otras porque se piensa que es natural; por ejemplo, que las mujeres sean las únicas responsables de la limpieza de la casa, o del cuidado de los hijos.

La costumbre ha llevado a las personas a no afrontar el conflicto hasta que la situación se pone tan tensa que explota y es más difícil de manejar. A esto se llama crisis de conflicto. (SEP, 2014d p. 186)

En la parte inferior de dicha página del libro texto, se representa la secuencia gráfica de la resolución del conflicto, en la cual el mensaje latente es que, si el origen del conflicto es que el hombre y la mujer tienen prisa, y deben salir de casa al mismo tiempo, la solución es que ella se quede a cuidar a la hija, y él salga a trabajar. En esta sección el contenido explícito es la crítica a la naturalización del papel de género de madre/ama de casa asignado a las mujeres, y el contenido implícito, es decir, el que expresa el currículo oculto, es que la mujer (madre/esposa) se debe quedar en el hogar al cuidado de hijos e hijas para solucionar el problema.

El libro Formación Cívica y Ética de cuarto grado de primaria (SEP, 2014c) contiene temas de derechos y salud-dentro de los cuales se plantea, de manera tangencial y ambiguamente, la educación sexual-, por ejemplo, en el bloque uno:

Niños y niñas cuidan de su salud e integridad personal ... has adquirido mayor confianza en ti porque conoces mejor tus derechos. Este conocimiento te da la facultad de evitar algún abuso que tus compañeros o alguien quiera ejercer contra ti. (SEP, 2014c, p. 9-11)

En nuestra interpretación, no es claro cómo las niñas y los niños, al saber sobre sus derechos, puedan lograr desarrollar su capacidad de gestión y de toma de decisiones, ya que, como hemos argumentado, una cosa es conocer y otra elegir, y una no lleva automáticamente a la otra. No sabemos si las personas autoras de este libro de texto, además de obviar que ya pueden prevenir el abuso, se referían también al abuso sexual. La propuesta de "código de conducta cuando use internet" (SEP, 2014c, p. 16) contiene lineamientos valiosos que podrían ayudar a evitar la explotación y el abuso sexual infantil, aunque no propicia la reflexión y queda en un decálogo sobre hacer/no hacer propio de la ética deontológica.

El tema de género se aborda introduciendo la definición como una construcción sociocultural: "Una diferencia que divide a la humanidad en dos partes casi iguales es la del sexo. Si hablamos acerca de diferencias biológicas entre hombres y mujeres, nos referimos al sexo; si son diferencias o expectativas culturales, al género" (SEP, 2014c, p. 13). No obstante, se continúa con un modelo binario y complementario, en el cual se refuerza la heterosexualidad obligatoria, la vida en pareja y la parentalidad como imprescindible. En cuanto a género, se explica que: 
En la medida en que existan más oportunidades educativas para mujeres y hombres, los papeles sociales y los oficios son ahora desempeñados por unas y otros. Tanto mujeres como hombres estudian y trabajan y, cuando forman pareja y establecen una familia, comparten las tareas domésticas. Esto ha creado mayor equidad en nuestro país. En la actualidad, las leyes de México establecen las mismas libertades para hombres y mujeres. (SEP, 2014c, p. 14)

Es atinado hablar de equidad, pues efectivamente no hay igualdad de condiciones ni de oportunidades; pero en la forma como se presenta el tema, pareciera que es una batalla ganada y del pasado, por lo que las niñas y los niños podrían recibir el mensaje de que hemos acabado con el patriarcado, y que la equidad es suficiente y no un medio para llegar a la igualdad.

El mismo libro de Formación Cívica y Ética de cuarto grado, en el bloque dos, denominado "El ejercicio de mi libertad y el respeto a los derechos propios y ajenos", menciona algunos derechos como libertad, educación, salud, información, reunión, libre tránsito y libertad de expresión. Se argumenta que:

Estos valores de la libertad de que hablamos son llamados por la ley: derechos humanos y sus garantías porque protegen las facultades que tienes como individuo para realizar aquello que para tu bien y el de los demás te parezca propicio. (SEP, 2014c, p. 33)

Señalamos que algunas definiciones del texto no son precisas y se abordan los derechos en función de las conductas, los límites, la autorregulación y el manejo de emociones. Por ejemplo, no se habla de que existen instrumentos nacionales e internacionales sobre derechos de las niñas y los niños, derechos de las mujeres, de las personas con discapacidad y de personas de la tercera edad a pesar de que en la evaluación hay un reactivo sobre el respeto a los derechos de estas personas (SEP, 2014c).

\section{Formación docente en género y sexualidad en docentes de primaria}

Al realizar las entrevistas, nos interesaba saber cómo el personal docente se apropia de la educación sexual y del concepto de género, y cómo lo aborda con el estudiantado, por lo que buscamos ideas que se dan por hecho, o que se encuentran atravesadas por el sentido común en los discursos del profesorado:

P: ${ }^{5}$ ¿En la primaria cómo y de qué manera se da la primera aproximación al tema de género?

\footnotetext{
${ }^{5}$ En los diálogos y testimonios la letra $\mathrm{P}$ se refiere a una pregunta por parte de quien investiga, $\mathrm{y}$ la $\mathrm{R}$ es la respuesta o intervención ofrecida por el sujeto informante.
} 
doi: http://dx.doi.org/10.15359/ree.21-2.11

URL: http://www.una.ac.cr/educare

CORREO: educare@una.cr

R:Si no me falla la memoria, en quinto año, cuando se empieza ver los cambios que van a sufrir los adolescentes, ponen ahí equidad de género, ahí el tema, como ponen ahí los ejemplos, de que varones solo hacían ciertos trabajos y como ahora las mujeres; se habla de equidad por el rezago que tienen las mujeres, pero como aquí hay mujeres taxistas entonces ya ven que si una mujer está manejando es por la equidad (profesora de sexto grado, primaria, Cancún, Quintana Roo).

Habíamos señalado que las conceptualizaciones sobre género pueden llevar a una mala interpretación al considerarlo únicamente como falta de oportunidades para acceder a un trabajo asalariado o recibir un salario igual al de los varones. En el testimonio anterior esto es evidente, ya que la docente se refiere a la equidad genérica en función del acceso de las mujeres a un empleo como el de taxista. Al indagar acerca de cómo se trata el tema de género con sus estudiantes, una profesora lo explicó de la siguiente manera:

R: El género se maneja como la diferencia entre el hombre y la mujer.

P: ¿Una diferencia social, biológica o cómo?

R: Social más bien, biológica no la manejan; lo manejan en sexualidad, y la diferencia entre uno y otro y equidad de género se maneja pero más social. Por ejemplo, que las mujeres antes llegaban a la primaria y ahora llegan a lo que es la carrera (profesora de quinto grado, primaria, Mérida, Yucatán).

Así, si bien se comprende que género es un concepto social, nuevamente se reduce a los papeles que desempeñan las mujeres en el ámbito laboral. Sería deseable que los grupos docentes comprendieran el género como la construcción sociocultural de la diferencia sexual -expresada principalmente por los genitales-, es decir, como el conjunto de ideas, valores y atributos que se asignan a las mujeres y los hombres con base en el cuerpo que aparentan tener. Decimos "aparentan" porque en realidad debido al uso de la ropa, para nadie es evidente que se posean genitales propios de un hombre o de una mujer, sin embargo, se presupone que existen dos clases de seres humanos: mujeres y hombres, y en función de esa aparente diferencia sexual se espera que actúen y desarrollen papeles sociales diferenciados; sin embargo, el género es algo más que actuaciones y roles:

El género, siguiendo a Joan Scott,encierra símbolos culturales queevocan representaciones diversas con relación al cuerpo, como pueden ser la pureza, la contaminación y la inocencia; envuelve también conceptos normativos que revelan interpretaciones de los significados de los símbolos, los cuales se enuncian en doctrinas religiosas, políticas, educativas, científicas y legales, entre otras. (Rosales, 2010, p. 29) 
Ahora bien, después de que el personal docente comprenda cabalmente el significado del concepto de género, habrá que encontrar la manera de explicárselo a estudiantes de primaria; el problema que percibimos es que desde una visión adultocéntrica, en general, se piensa que quienes se encuentran entre cuarto y sexto grado de primaria no comprenden ciertos conceptos, aunque se supone que alrededor de los 11 años ya se posee la capacidad cognitiva de abstracción. Según Cano (2007), se debe abordar "tomando en cuenta el largo proceso evolutivo del pensamiento infantil" (p. 162).

Vygotski, citado en Cano (2007) señala que:

En su formación intervienen todas las funciones intelectuales en una combinación original, cuyo factor central es el uso funcional de la palabra como medio de orientación deliberada de la atención, de la abstracción, de la selección de atributos y de su síntesis y simbolización con ayuda del signo. (p. 162)

En relación con lo anterior, consideramos que la abstracción de conceptos debería ser más evidente en los programas educativos de los últimos grados de primaria. Se requiere cierta capacidad de abstracción para estudiar el concepto de género, pero puede ser asequible para el estudiantado con guías didácticas y pedagógicas pertinentes. Si bien se han incluido contenidos de género en los libros de texto, no son claras las diferencias entre perspectiva, equidad, igualdad, papel o rol de género, estereotipos e identidad genérica, por lo que consideramos que es necesario brindar cursos de formación y actualización sobre métodos y didácticas para que los cuerpos docentes, a su vez, puedan replicar los temas con sus estudiantes. No se puede pretender que el estudiantado comprenda ciertos conceptos si las personas responsables de impartir los temas no los han estudiado con profundidad y no poseen la capacidad para hacerlos accesibles. Los libros o guías del maestro o maestra no cumplen con la función que deberían tener, a saber, la de ser manuales didácticos en los que docentes puedan encontrar métodos para explicar conceptos y contenidos. En la actualidad funcionan como una extensión de actividades sugeridas para el trabajo en el aula.

En cuanto a los contenidos de EIS, se necesita subrayar las diferencias entre sexo y sexualidad, e inclusive con género, pues el profesorado continúa teniendo dificultades para comprenderlas:

P: ¿Cómo explicaría la diferencia entre sexo, sexualidad y género a sus estudiantes?

R: ¿El sexo? ¿en cuál sentido? ¿por el género o por tener relaciones sexuales?

P: Si un niño le pregunta cuál es la diferencia entre sexo, sexualidad y género ¿qué le dice? 
doi: http://dx.doi.org/10.15359/ree.21-2.11

URL: http://www.una.ac.cr/educare

CORREO: educare@una.cr

R: Bueno, yo... le digo que sexo se ha manejado como concepto de hombre y mujer, o que sexo es como si fuera a tener relaciones sexuales. Sexualidad [negritas añadidas] lo manejo como el concepto de conocer cómo es el cuerpo de cada uno. Al menos así les digo en mi particular forma de ver... sexo se va a lo que es género de hombre y mujer, eso es el género [negritas añadidas] (profesora de sexto grado, primaria, Cancún, Quintana Roo).

El sexo ha sido definido como el "carácter de los seres orgánicos por el cual pueden ser machos o hembras ... órganos sexuales externos ... conjunto de prácticas encaminadas a obtener placer sexual" (Moliner, 2000, p. 1277). Así, las acepciones de sexo se refieren al conjunto de características biológicas que distinguen a una mujer de un hombre y viceversa, así como a la actividad sexual (Rosales, 2011). Género es un tanto más polisémico, pues indica: el género gramatical femenino, masculino o neutro; la perspectiva de género, que consiste en una mirada enfocada a lograr la igualdad entre todas las personas (vigente en las políticas públicas), y; la categoría de género, útil para el análisis sobre las construcciones socioculturales de la diferencia sexual (Rosales, 2011) entre otros. La sexualidad, por su parte, constituye un concepto complejo queva desde las miradas, palabras, caricias, besos, abrazos, relaciones sexuales (no necesariamente coitales), que se expresa en solitario, en pareja, en grupo; a través de fantasías, sueños eróticos, deseos y prácticas. Puede ser causante de placer, dolor, satisfacción, insatisfacción, amor o violencia, y ser un asunto privado (e.g. propio de la alcoba) o público (e.g. prácticas swinger). Mediante las entrevistas efectuadas a docentes constatamos que su formación es insuficiente:

R: Cuando vamos a ver lo que es la sexualidad, les traigo un dulce, les pregunto que si alguien sabe a qué se refiere esta palabra y pues empiezan a decir: tratan sobre las relaciones sexuales o tratan sobre los cambios que estamos viviendo (profesora de sexto grado de primaria, Mérida, Yucatán).

R: Les explico que la sexualidad es conocer tus cambios como ser humano, que tienes como mujer y como hombre. Porque yo les menciono que en la época de los abuelos o de los papás, no se les hablaba sobre ello, yo les digo a ellos, fíjense que el libro de quinto y sexto año hubo problemas hace años cuando se hizo la modificación, porque cómo le iban hablar a los niños sobre la menstruación, o que en el caso de los varones que iban a tener erección (profesora de quinto grado, primaria, Mérida, Yucatán).

R: De la sexualidad, por ejemplo, les hablamos de a qué edad empiezan ellos a cambiar. En el caso de los varones a qué edad ya les empieza a salir lo que es el vello, en qué partes aparece, por ejemplo, ya empiezan a producir también lo que son los espermatozoides y que los famosos sueños húmedos. En caso de las mujeres menciona mucho el caso de la menstruación, cómo deben de cuidarse, les crecen los senos, que la cadera, todo eso (profesor de quinto grado de primaria, Cancún, Quintana Roo). 
En los testimonios anteriores se puede apreciar la confusión entre los conceptos de género, sexo y sexualidad. En sus apreciaciones, la sexualidad se refiere (y así la explican a sus estudiantes) a conocer el cuerpo y sus cambios anatómicos y fisiológicos (crecimiento de vello, senos; menstruación y eyaculación), así como a las relaciones sexuales. El género es ser hombre o mujer y el sexo....también; aunque una noción más amplia de sexo se refiere a tener relaciones sexuales... igual que la sexualidad.

Al indagar sobre las necesidades de formación en cuanto a género, el personal docente entrevistado afirmó que requiere de materiales educativos en los cuáles pueda disipar sus dudas, y en donde se profundice sobre el tema:

P: ¿Y cómo qué dudas tienen los docentes al impartir el tema de género?

R: Pues yo creo que muchas, cómo le diré, a mí me gustaría que dieran un poquito de más información, o sea, por ejemplo, cómo hacer para que las niñas se valoren un poco más, que ellas sientan que pueden hacer las cosas, como en la perspectiva, que sepan que pueden, como los hombres (profesora de sexto grado de primaria, Mérida, Yucatán).

P: Entonces a los docentes ¿les dan formación sobre perspectiva de género?

R: De hecho, todo se va como dice el plan y el programa, en como está en el libro y ya depende del maestro si quiere informar o no.

P: ¿Y en el libro del maestro les explican más sobre el concepto de género?

R: El libro del maestro se va por materias y nada más te sugiere cómo evaluar al alumno y qué actividad les puedes poner de tarea. Pero así que te diga mira aborda el tema de esta manera o dile al muchacho cómo va a ser ese tema, no; solo es una guía de cómo vas a hacer las cosas y cómo vas a evaluar (profesor de quinto grado de primaria, Cancún, Quintana Roo).

Las personas informantes también hablaron sobre contenidos de educación sexual presentes en el currículo de quinto y sexto grados de primaria: la evolución humana, la reproducción, los cambios físicos y psicológicos que suceden a las jóvenes y los jóvenes, y de los temas que consideran relevantes en cuanto a formación sobre EIS:

R: Falta que nos hablen más sobre educación sexual, porque si a mí me dan esa información yo se las puedo dar a los niños (profesora de sexto grado de primaria, Mérida, Yucatán). 
doi: http://dx.doi.org/10.15359/ree.21-2.11

URL: http://www.una.ac.cr/educare

CORREO: educare@una.cr

R: Ahorita en efecto menciona nada más lo que son los cambios físicos, intelectuales, que tienen los muchachos. Pero las relaciones sexuales solo las manejan como tener contacto entre hombre y mujer, sobre todo que si hay cariño, no ampliaron más (profesor de quinto grado de primaria, Cancún, Quintana Roo).

R: De hecho consideraría que como maestros en ese nivel se nos dieran más cursos sobre sexualidad, porque he tomado pláticas, a veces con compañeros, tuve un curso de Formación Cívica y Ética, y a como vamos ahorita en la sociedad normalmente los maestros varones sienten miedo de dar quinto y sexto año porque dicen que a veces el padre de familia considera que están enamorando a las muchachitas y que ellos sienten cierto temor para dar esos temas ante las muchachas y los niños (profesora de sexto grado de primaria, Mérida, Yucatán).

R: Que hubiera un libro sobre didáctica de la sexualidad, en el caso de la sexualidad, y sobre todos esos temas de género, sí, sería bueno, bastante. Con ciertas actividades, en dado caso, donde pudiera trabajar con los muchachos (profesora de sexto grado, primaria, Cancún, Quintana Roo).

P: ¿Ustedes son autodidactas, estudian y van modificando los contenidos de un año a otro?

R: Yo voy a mi plan y mi programa, ya ve que venden libros particulares y yo compré el que le dicen Santillana [se refiere a la Editorial], que es el que según se apegaba a lo que pedía plan y programa, y yo, al menos yo, cuando pasan los alumnos a quinto grado ya vemos más temas de sexualidad. Pero ahora que quieren que nos formemos más iy cómo le vamos a hacer si no hay dónde buscar información; no hay cursos de formación ni de actualización tampoco (profesora de sexto grado, primaria, Cancún, Quintana Roo).

Al inicio de este artículo subrayamos la importancia de incluir otros temas en los currículos de primaria, particularmente la trata sexual de niñas y niños, la prostitución infantil, la pedofilia y la pederastia. En las entrevistas exploramos también sobre el abuso sexual, ya que, en la Agenda sectorial de educación integral de la sexualidad, con énfasis en prevención del embarazo en adolescentes se menciona que de primero a cuarto grado se incluyeron contenidos sobre el abuso sexual (SEP, 2015).

P: ¿Les hablan del abuso sexual dentro de los contenidos de quinto grado?

R: Así abierto no, es que todavía hay temor de hablar de esos temas. 


\section{P: ¿Es un tema que hace falta?}

R: Demasiado, de hecho, sí, sería el principal, y además, hablarles de las relaciones sexuales, de los anticonceptivos, de las pastillas, de los embarazos en adolescentes, y darles la información para no embarazarse, para que pudieran prevenirlo; pero no les hablamos de eso porque son temas que tenemos temor de hablarlos (profesora de sexto grado de primaria, Mérida, Yucatán).

\section{Conclusión}

En este artículo subrayamos la necesidad de revisar los contenidos de EIS de los libros de texto de primaria, específicamente de cuarto, quinto y sexto grado de primaria en México, debido a que sus alcances son limitados. De la misma manera, destacamos la imperante necesidad de formar maestros y maestras competentes en el campo de la educación de la sexualidad con perspectiva de género, intentando mostrar que ambos aspectos son relevantes en las estrategias planteadas por la política pública de educación mexicana. Específicamente la Agenda sectorial de educación integral de la sexualidad, con énfasis en la prevención del embarazo en adolescentes (SEP, 2015) planteó que en cada uno de los grados de educación básica se trabajarían las competencias para la vida, la EIS, diversidad, equidad, prevención de violencia y derechos humanos, por lo que tras la revisión exhaustiva de los materiales pudimos constatar que no se están tratando a cabalidad tales conocimientos, habilidades y actitudes. Consideramos que los contenidos de los libros de texto deben ir más allá de una aproximación biologicista con énfasis en la prevención del embarazo y las ITS.

Los relatos de los sujetos informantes, profesorado en servicio, dan testimonio del currículo oculto, pues la falta de información veraz y de aproximaciones socioculturales a la EIS no solo genera vacíos importantes en la formación de estudiantes, sino que perpetúa la transmisión de estereotipos de género, ya que el trabajo de la sexualidad implica, en primer lugar, un profundo proceso de autoanálisis y de cuestionamiento permanente sobre las propias creencias, prejuicios y privilegios desde nuestro "ser hombre" o "ser mujer". De no llevar a cabo tales reflexiones, aumentan las probabilidades de que los contenidos que se enseñan estén dominados por valores y creencias de las profesoras y los profesores.

En general, los libros de texto revisados reducen la sexualidad a la reproducción y a la heteronorma; fallan en brindar herramientas útiles para prevenir el abuso sexual; promueven someramente la reflexión y el conocimiento del cuerpo -no así del placer, de la vinculación, y de sus derechos sexuales y reproductivos-; fracasan en denunciar la desigualdad entre hombres y mujeres con el uso/abuso correspondiente del poder $y$, promueven la idea de que los grupos de estudiantes se encuentran en un período crítico, contradictorio y con difusión identitaria 
doi: http://dx.doi.org/10.15359/ree.21-2.11

URL: http://www.una.ac.cr/educare

CORREO: educare@una.cr

e inmadurez emocional pues son "adolescentes". Quizá, un primer paso, sea reconocer que estudiantes, docentes y quienes investigamos encontramos a diario encrucijadas en las cuales es necesario decidir; que no es privativo de una etapa evolutiva sentir miedo e inseguridad; que nuestra condición humana nos orilla a crear prejuicios y a vivir paradojas, y que la EIS, a cualquier nivel educativo, trae siempre consigo la posibilidad de encontrarnos cara a cara con nuestra historia para hacer un alto en el camino y crear experiencias más empáticas y respetuosas de la diversidad. Entre otras cosas, consideramos que dentro de los temas de sexualidad y género que se imparten en primaria han quedado pendientes la trata sexual de niñas y niños, la prostitución infantil, la pedofilia y la pederastia; problemáticas a las que están expuestos estudiantes de primaria. En cuanto a la formación docente, apuntamos que se requiere diseñar cursos de EIS con enfoques de género y derechos, que sean impartidos en las escuelas normales (formadoras de docentes) y en las universidades con carreras de educación, con miras a incidir en los conocimientos que transmite el profesorado a estudiantes en los distintos niveles educativos ya que, hasta 2016, la inclusión curricular de estas temáticas continuaba siendo limitada.

\section{Referencias}

Cano, A. (2007). Cognición en el adolescente según Piaget y Vygotski. ¿Dos caras de la misma moneda? Boletim Academia Paulista de Psicologia, 27(2), 148-166. doi: https://doi. org/10.4067/s0718-22362004000200004

Dávila, O. (2004). Adolescencia y juventud: De las nociones a los abordajes. Última Década, 12(21), 83-104. Recuperado de http://www.scielo.cl/pdf/udecada/v12n21/art04.pdf

Díaz, Á. (2006). La educación en valores. Avatares del curriculum formal, oculto y los temas transversales. Revista Electrónica de Investigación Educativa, 8(1), 1-16- Recuperado de http://www.redalyc.org/articulo.oa?id=15508101

Freud, S. (1989). Teorías sexuales de los niños. En S. Freud (Aut.), Sexualidad infantily neurosis (pp. 15-31). México: Alianza Editorial.

Freud, S. (1994). La sexualidad infantil. En S. Freud (Aut.), Tres ensayos para una teoría sexual (pp. 40-71). México: Alianza Editorial.

México Gobierno de la República. (2015). Estrategia nacional para la prevención del embarazo en adolescentes. Recuperado de http://www.sedesol.gob.mx/work/models/SEDESOL/PDF/ ENAPEA 0215.pdf

Moliner, M. (2000). Diccionario de uso del español. Madrid: Editoral Gredos.

Parga, L. (2008). La construcción de los estereotipos del género femenino en la escuela secundaria. México: UPN. 
Rosales, A. L. (2010). Sexualidades, cuerpo y género en culturas indígenas y rurales. México: UPN. Recuperado de http://editorial.upnvirtual.edu.mx/index.php/9-publicaciones-upn/136sexualidades-cuerpo-y-genero-en-culturas-indigenas-y-rurales

Rosales, A. L. (2011). Sexualidad, derechos y violencia. Enfoques y conceptos para la enseñanza. México: UPN. Recuperado de http://www.cetis114.edu.mx/TUTORIAS 2014/ IGUALDAD\%20DE\%20GE\%CC\%80NERO\%20Y\%20PREVENCION\%20DE\%20LA\%20 VIOLENCIA/IGUALDAD\%20DE\%20GENERO/LIBROS\%20PDF/Sexualidad, $\% 20$ derechos\%20y\%20violencia.pdf

Rubio, E. (1994). Introducción al estudio de la sexualidad humana. En Consejo Nacional de Población (Ed.), Antología de la sexualidad humana, I (pp.17-46). México: Porrúa.

Salinas-Quiroz, F. (2014). Dificultades resistenciales y contrarresistenciales en el tratamiento de niños latentes. Revista Chilena de Psicoanálisis, 31(2), 161-169. Recuperado de http://www. apch.cl/2012/images/stories/documentos/revista/vol31dic/Salinas\%20dificultades.pdf

Secretaría de Educación Pública (SEP). (2014a). Ciencias naturales. Cuarto Grado (4ª Ed.). México: Autor. Recuperado de http://descargas.cicloescolar.com/ciencias-naturales-cuarto-grado2016-2017-pdf/

Secretaría de Educación Pública (SEP). (2014b). Ciencias naturales. Quinto Grado (3a Ed.). México: Autor. Recuperado de http://librossep.com/ciencias-naturales-libro-texto-quinto-grado2016-2017-pdf/

Secretaría de Educación Pública (SEP). (2014c). Formación cívica y ética (4a Ed.). México: Autor. Recuperado de http://librossep.com/formacion-civica-etica-libro-texto-cuarto-grado2016-2017-pdf/

Secretaría de Educación Pública (SEP). (2014d). Formación cívica y ética (5a ed.). México: Autor. Recuperado de http://librossep.com/formacion-civica-etica-libro-texto-quinto-grado2016-2017-pdf/

Secretaría de Educación Pública (SEP). (2014e). Formación Cívica y Ética. Sexto Grado. México: Autor. Recuperado de http://librossep.com/formacion-civica-etica-libro-texto-sextogrado-2016-2017-pdf/

Secretaría de Educación Pública (SEP). (2014f). Ciencias Naturales, Sexto Grado (3a ed.). México: Autor. Recuperado de http://librossep.com/ciencias-naturales-libro-texto-sexto-grado2016-2017-pdf/

Secretaría de Educación Pública (SEP). (2015). Agenda sectorial de educación integral de la sexualidad, con énfasis en la prevención del embarazo en adolescentes (documento inédito). México: Secretaría de Educación Pública, Subsecretaría de Planeación y Evaluación de Política Educativas, Dirección General Adjunta de Igualdad de Género. 